
UNITED STATES DEPARTMENT OF COMMERCE - Charles Sawyer, Secretary

\section{Charts of Compressibility Factors and Charts Showing Quantities Delivered by Commercial Cylinders for Hydrogen, Nitrogen, and Oxygen}

by Harold J. Hoge, Cyril H. Meyers, and Robert E. McCoskey

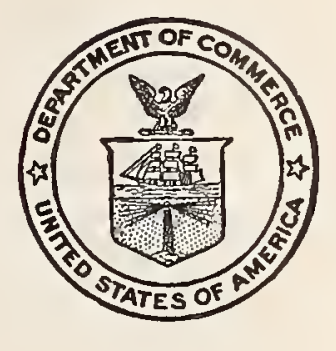

Miscellaneous Publication M191

Issued November 17, 1948

For sale by the Superintendent of Documents, U. S. Government Printing Office, Washington 25. D. C. 


\section{Contents}

I. Introduction

II. Description of charts $\ldots \ldots \ldots \ldots$

III. Examples of use of the charts ...

IV. References $\ldots \ldots \ldots \ldots \ldots$ 


\title{
Charts of Compressibility Factors and Charts Showing Quantities Delivered by Commercial Cylinders, for Hydrogen, Nitrogen, and Oxygen
}

\author{
by Harold J. Hoge, Cyril H. Meyers, Robert E. McCoskey
}

\begin{abstract}
For each of the gases hydrogen, nitrogen, and oxygen, two oharts are given. The first gives directly the number of standard cubic feet of the gas which a cylinder will deliver. The second chart gives values of the compressibility factor $Z=P V / n R T$ and of the density $\rho$. Examples of the use of the charts are given, also numerical values of constants used in the preparation of the charts or needed in the solution of problems.
\end{abstract}

\section{Introduction}

The six charts published herewith present in a form convenient for engineering use some of the results of rather extensive investigations and analyses of the existing data for hydrogen, nitrogen, and oxygen. The work on hydrogen was performed by Woolley, Scott, and Brickwedde [1]. ${ }^{1}$ That on nitrogen was done chiefly by R. B. Scott and H. W. Woolley and has not been published. The work on oxygen was performed by Cyril H. Meyers [2].

\section{Description of Charts}

The first three charts $(1,2$, and 3$)$ give the number of standard cubic feet of gas which a cylinder will deliver when the pressure and temperature of the gas and the volume of the cylinder are known. The last three charts $(4,5$, and 6$)$ give values of the compressibility factor $Z=P V / n R T$ and are useful in solving a wide variety of gas-law problems.

Charts 1, 2, and 3 are for a cylinder volume of 2,640 cubic inches $(1.528 \mathrm{cu} \mathrm{ft})$. This is approximately the minimum volume of the commonest commercial cylinder. The average volume as given in table 1 is about 1 percent greater. The quantity which a cylinder will deliver is equal to its contents less the amount remaining in the cylinder when the gage pressure has fallen to zero, that is, when the absolute pressure has fallen to atmospheric. In preparing charts 1, 2, and 3, gage pressure was taken to be equal to absolute pressure minus $14.696 \mathrm{lb}$ per sq in., and the gas remaining in the cylinder was assumed to be at $70^{\circ} \mathrm{F}$. The accuracy of these charts is greater than the accuracy with which they can be conveniently read. Hence the only error introduced by the use of these charts is the reading error.

Charts 1, 2, and 3 may be used for cylinders having volumes different from 2,640 cu in. provided the quantities delivered appearing on the charts are mlti plied by $V / 2640$, where $V$ is the volume of the given cylinder in cubic inches. Table 1 contains data on a number of the more common sizes of commercial cylinders normally used for oxygen, hydrogen, nitrogen, helium, neon, argon, and other gases. This table was compiled from data kindly furnished us by Franklin R. Fetherston of the Compressed Gas Manufacturers' Association. In general the cylinders listed are manufactured to comply with the Interstate Commerce Commission's $3 \mathrm{~A}$ or $3 \mathrm{AA}$ specifications. These are seamless drawn cylinders, the A type being steel of less than 0.55 percent carbon content, and the AA type alloy steels which permit the cylinder to be lighter. In most cases the tolerances of an individual manufacturer on cylinder volume are smaller than the tolerances given in the table, the minimum volume in the table generally coming from one manufacturer and the corresponding maximum volume from another. The volumes given in the table are only approximate and no estimate of their accuracy can be given. It is interesting to note that about the only volume on which there was general agreement was the $2,640 \mathrm{cu}$ in. minimum volume of the most common commercial cylinder. Column 4 of the table contains values of the factor $V / 2640$.

\footnotetext{
1 Figures in brackets indicate the literature references at the end of this paper.
} 
TABIE 1. Data on some common commercial gas cylinders used for oxygen, hydrog̉en, nitrogen, helium, neon, argon, and other gases

\begin{tabular}{|c|c|c|c|c|c|c|c|c|}
\hline \multicolumn{3}{|c|}{ Volume } & \multirow{2}{*}{$\begin{array}{l}\text { Multiplying } \\
\text { factor a for } \\
\text { use with } \\
\text { charts } 1,2,3\end{array}$} & \multirow{2}{*}{$\begin{array}{c}\text { Inside } \\
\text { diameter }\end{array}$} & \multirow{2}{*}{ Length b } & \multirow{2}{*}{$\begin{array}{l}\text { Service } \\
\text { pressure }\end{array}$} & \multirow{2}{*}{$\begin{array}{c}\text { Rated capacity for } \\
\text { oxygen }\end{array}$} & \multirow{2}{*}{$\begin{array}{l}\text { Rated capacity for } \\
\text { medical oxygen }\end{array}$} \\
\hline Min & $\Lambda \mathrm{vg}$ & $\operatorname{Max}$ & & & & & & \\
\hline $\begin{array}{l}\text { cuin. } \\
168 \\
278 \\
315\end{array}$ & $\begin{array}{l}\text { cu in. } \\
\quad 173 \\
290 \\
325\end{array}$ & $\begin{array}{r}c u \text { in. } \\
180 \\
303 \\
332\end{array}$ & $\begin{array}{r}0.0636 \\
.1053 \\
.1193\end{array}$ & $\begin{array}{l}\text { in. } \\
3^{15 / 10} \\
3^{15} / 16 \\
41 / 8\end{array}$ & $\begin{array}{l}\text { in. } \\
163 / 4 \\
25^{3 / 4} \\
261 / 2\end{array}$ & $\begin{array}{l}l b \text { per } s q \text { in. } \\
2,015 \\
2,015 \\
2,015\end{array}$ & $\begin{array}{c}\text { std cu ft } \\
14 \\
23 \\
26\end{array}$ & $\begin{array}{l}80 \text { or } 95 \\
130 \text { or } 165 \\
150\end{array}$ \\
\hline 1,320 & 1,352 & 1,386 & .5000 & $65 / 8$ & 43 & $\left\{\begin{array}{l}2,015 \\
2,265\end{array}\right.$ & $\begin{array}{l}110 \\
125\end{array}$ & - \\
\hline 2,340 & 2,390 & 2,420 & .8864 & 8 & 51 & & 220 & $\begin{array}{l}1,150 \text { or } 1,400 \\
1,300\end{array}$ \\
\hline 2,640 & 2,666 & 2,720 & 1 & $8 \frac{1}{2}$ & 51 & $\begin{array}{l}2,015 \\
2,265\end{array}$ & $\begin{array}{l}\left(206 \text { for } \mathrm{N}_{2}\right) \\
\left(192 \text { for } \mathrm{H}_{2}\right) \\
250\end{array}$ & -10-10- \\
\hline 2,970 & 3,026 & 3,066 & 1. 1250 & $83 / 4$ & 55 & 2,400 & 300 & 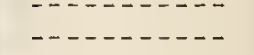 \\
\hline 3,955 & 4, 006 & $\begin{array}{r}4,075 \\
5\end{array}$ & 1. 4981 & 10 & $\begin{array}{c}56 \\
\text { d } 201 / 1 \text { in }\end{array}$ & 2,400 & 400 & $-\ldots-\ldots---$ \\
\hline 14,925 & 15,000 & 15,075 & 5.6534 & $81 / 16$ & $20 \mathrm{ft} 61 / 4 \mathrm{in}$ & 2,400 & 1,500 & ------ \\
\hline
\end{tabular}

- Based in all cases on the minimum volume.

b Over all length, not including valve or protecting cap.

- One standard gallon equals $231 / 1728$ std $\mathrm{ft}^{3}$ but rated capacity for medical oxygen is based on lower pressures than are uscd for industrial oxygen.

d A tube necked at both ends.

The use of the compressibility factor $Z=P V / n R T$, which varies only slowly with temperature and pressure, permits a great increase in accuracy of the results which may be obtained from a chart of a given size, as compared with the direct-reading charts 1,2, and 3. The Z-charts 4, 5, and 6 cover a much greater range of pressures and temperatures than the first three charts.

Many numerical problems can be solved without assigning a value to the gas-constant $R$, because the value appears on both sides of the equation and cancels out. When a numerical value is required, it should be consistent with the units employed. If pressure is expressed in pounds per square inch absolute, volume in cubic feet, temperature in degrees Fahrenheit-absolute $\left({ }^{\circ} \mathrm{F}+459.69\right)$ and quantity of gas in pound-moles (one pound-mole is a number of pounds equal to the molecular weight of the gas),

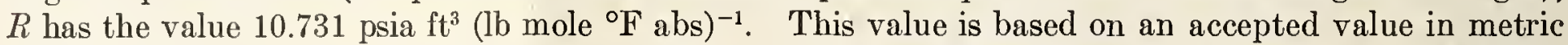
units of $82.0567 \mathrm{~atm} \mathrm{~cm}^{3}$ (gm mole $\left.{ }^{\circ} \mathrm{K}\right)^{-1}$ which is for pressures expressed in atmospheres, volume in cubic centimeters, temperature in degrees Kelvin $\left({ }^{\circ} \mathrm{C}+273.16\right)$, and quantity of gas in gram-moles.

The number of moles $n$ (gram-moles or pound-moles) of gas in any given volume $V$ may be found from the equation $n=P V / R T Z$. Multiplying by the molecular weight $M$ gives the mass of gas $W=$ $n M=P V M / R T Z$. If engineering units are used $n$ is in pound-moles and $W$ in pounds, while if metric units are used $n$ will be in gram-moles and $W$ in grams. Table 2 contains densities calculated with the above formulas, together with other relevant data for use with the charts.

TABLE 2. Molecular weights of hydrogen, nitrogen, and oxygen, with densities and Z-values at standard conditions

\begin{tabular}{|c|c|c|c|c|c|c|}
\hline \multirow{2}{*}{ Substance } & \multirow{2}{*}{ Molecular weight } & \multicolumn{2}{|c|}{ At $70^{\circ} \mathrm{F}$ and $1 \mathrm{~atm}$} & \multicolumn{3}{|c|}{ At $0^{\circ} \mathrm{C}$ and $1 \mathrm{~atm}$} \\
\hline & & $z$ & lb per cu ft & $Z$ & $\mathrm{~g}$ per $1,000 \mathrm{~cm}^{8}$ & moles per $1,000 \mathrm{~cm}^{3}$ \\
\hline $\begin{array}{l}\mathrm{H}_{2} \\
\mathrm{~N}_{2} \\
\mathrm{O}_{2}\end{array}$ & $\begin{array}{l}2.016 \\
28.016 \\
32\end{array}$ & $\begin{array}{l}1.0006 \\
0.9998 \\
0.9993\end{array}$ & $\begin{array}{l}0.005209 \\
0.07245 \\
0.08279\end{array}$ & $\begin{array}{l}1.000618 \\
0.999551 \\
0.999051\end{array}$ & $\begin{array}{l}0.08989 \\
1.2505 \\
1.42900\end{array}$ & $\begin{array}{r}0.044586 \\
.044634 \\
.044656\end{array}$ \\
\hline
\end{tabular}

Lines of constant density are plotted on the $Z$-charts. For these the unit of density is the density of the gas at $70^{\circ} \mathrm{F}$ and 1 atmosphere (14.696 psia). To convert a density read from the chart to $\mathrm{lb}$ per cu ft, multiply by the appropriate factor in column 4 of table 2 .

Three examples of the use of the charts will be given. 


\section{Examples of Use of the Gharts}

1. A $2,640 \mathrm{cu}$ in. cylinder contains oxygen at a gage pressure of $1,850 \mathrm{psi}$ and $63^{\circ} \mathrm{F}$. How many standard cubic feet of oxygen will the cylinder deliver? On chart 1 the point corresponding to 1,850 psi and $63^{\circ} \mathrm{F}$ is located. The horizontal line through this point corresponds to $208.0 \mathrm{cu} \mathrm{ft}$, which is the quantity the cylinder will deliver.

2. A $2,640 \mathrm{cu}$ in. cylinder contains hydrogen at a gage pressure of 2,100 psi and $80^{\circ} \mathrm{F}$. A smaller (evacuated) cylinder (318 cu in.) is to be filled from the larger one. To what pressure can the smaller cylinder be filled? Neglect the volume of the connecting line and assume that sufficient time is allowed for the hydrogen in both cylinders to reach $80^{\circ} \mathrm{F}$ while the cylinders are still connected. Assuming atmospheric pressure to be $15 \mathrm{psi}$, the absolute pressure in the large cylinder before transfer is 2,115 psi. On chart 4 the point corresponding to this pressure and to a temperature of $80^{\circ} \mathrm{F}$ is located. The density, $\rho_{1}$, at this point is 130 . The volume of the two cylinders together is $2,640+318=2,958 \mathrm{cu}$ in. Since for a fixed mass, density is inversely proportional to volume, the final density $\rho_{2}$ after the two cylinders are connected is given by $\rho_{2} / 130=2640 / 2958$, whence $\rho_{2}=116$. The point corresponding to this density and to a temperature of $80^{\circ} \mathrm{F}$ is located. The pressure at this point is found to be 1,875 psi (abs), or 1,860 psi (gage), which is the highest pressure to which the smaller cylinder can be filled by connecting it with the large one. This type of calculation is often sufficiently accurate, but it does not make use of the full accuracy obtainable with the chart. To obtain the highest computational accuracy the values of $Z$ are read at the points representing the initial and final conditions and substituted into the equation $P_{2} V_{2} / T_{2}=\left(P_{1} V_{1} / T_{1}\right)\left(Z_{2} / Z_{1}\right)$. Since $T_{1}=T_{2}$ this gives simply $P_{2} \times 2,958=2,115 \times$ $2,640 \times(1.078 / 1.088)$, whence $P_{2}=1,870$ psi abs or 1,855 psi (gage).

3. A cylinder with a volume of $1.528 \mathrm{cu}$ ft contains oxygen at a pressure of 2,150 psi (gage) and a temperature of $75^{\circ} \mathrm{F}$. It is required to transfer $9.2 \mathrm{lb}$ of this gas to a chamber where a mixture of gases is being made up. To what pressure should the cylinder be emptied, assuming the temperature to remain constant? Solution: Assume atmospheric pressure=14.7 psi. Then the absolute pressure is $2150+14.7=2164.7$ psia. The total mass of gas in the cylinder is $W=n M=P V M / R T Z$. The value of $Z$ is found from chart 6 to be 0.9435 , while $T=75+459.69=534.69^{\circ} \mathrm{F}$ abs. Substituting in the equation $P V M / R T Z=(2,164.7 \times 1.528 \times 32) \div(10.731 \times 534.69 \times 0.9435)=19.55 \mathrm{lb}$. When $9.2 \mathrm{lb}$ has been removed, $19.55-9.2=10.35 \mathrm{lb}$ will remain in the cylinder. The same equation is now used again to give the pressure $P$ when $10.35 \mathrm{lb}$ of oxygen remains in the cylinder. This is $P=W R T Z / V M$. The value of $Z$ is not yet known, so it is first assumed to be 1 . Substituting, $P=(10.35 \times 10.731 \times$ $534.69 \times 1) \div(1.528 \times 32)=1,214.6$ psia. This is a first approximation to $P$. Using it, a value of $Z$ is read from the chart and the calculation of $P$ repeated with this value of $Z$.

Successive approximations are continued until it is found that with $Z=0.9595$ and $P=1,165.4$ psia, no further change in $P$ occurs. Subtracting 14.7 psi gives $1,150.7$ psi for the gage pressure to which the cylinder should be emptied. In actual practice, removal of a part of the gas would cool that which remained in the cylinder, so that additional small amounts of gas would have to be let out of the cylinder as it warmed to $75^{\circ} \mathrm{F}$, in order to keep the pressure at $1,150.7 \mathrm{psi}$.

The convergence of the procedure of successive approximations may be speeded up by using the lines of constant density given on the chart to find the starting value of $Z$. Since the mass of gas in the cylinder is proportional to the density we have $\rho_{2} / \rho_{1}=W_{2} / W_{1}=10.35 / 19.55$. The initial density $\rho_{1}$ at $2,164.7 \mathrm{psia}$ and $75^{\circ} \mathrm{F}$ is 154 . Hence the desired final density $\rho_{2}=81.5$. At this density and $75^{\circ} \mathrm{F}$. the chart gives $Z=0.959$, which is a much better starting value of $Z$ than 1 .

Procedures for using the $Z$-charts for other types of problems may be worked out by the user. The charts will be found adaptable to the solution of almost any P-V-T problem involving $\mathrm{H}_{2}, \mathrm{~N}_{2}$, or $\mathrm{O}_{2}$ gases in the ranges covered.

\section{References}

[1] Harold W. Woolley, Russell B. Scott, and F. G. Brickwedde. A compilation of thermal properties of hydrogen in its various isotopic and ortho-para modifications. J. Research NBS 41, (1948) RP 1932.

[2] Cyril H. Meyers, Pressure-volume-temperature data for oxygen. J. Research NBS 40, 457 (1948) RP1891. 
Chart 1. Hydrogen gas. Chart giving the quantity of gas which an ordinary cylinder (2640 cu in.) will deliver.

Chart 2. Nitrogen gas. Chart giving the quantity of gas which an ordinary cylinder (2640 cu in.) will deliver.

Chart 3. Oxygen gas. Chart giving the quantity of gas which an ordinary cylinder (2640 cu in.) will deliver.

Chart 4. Hydrogas gas. Chart giving the compressibility factor $Z=P V / n R T$.

Chart 5. Nitrogen gas. Chart giving the compressibility factor $Z=P V / n R T$.

Chart 6. Oxygen gas. Chart giving the compressibility factor $Z=P V / n R T$. 



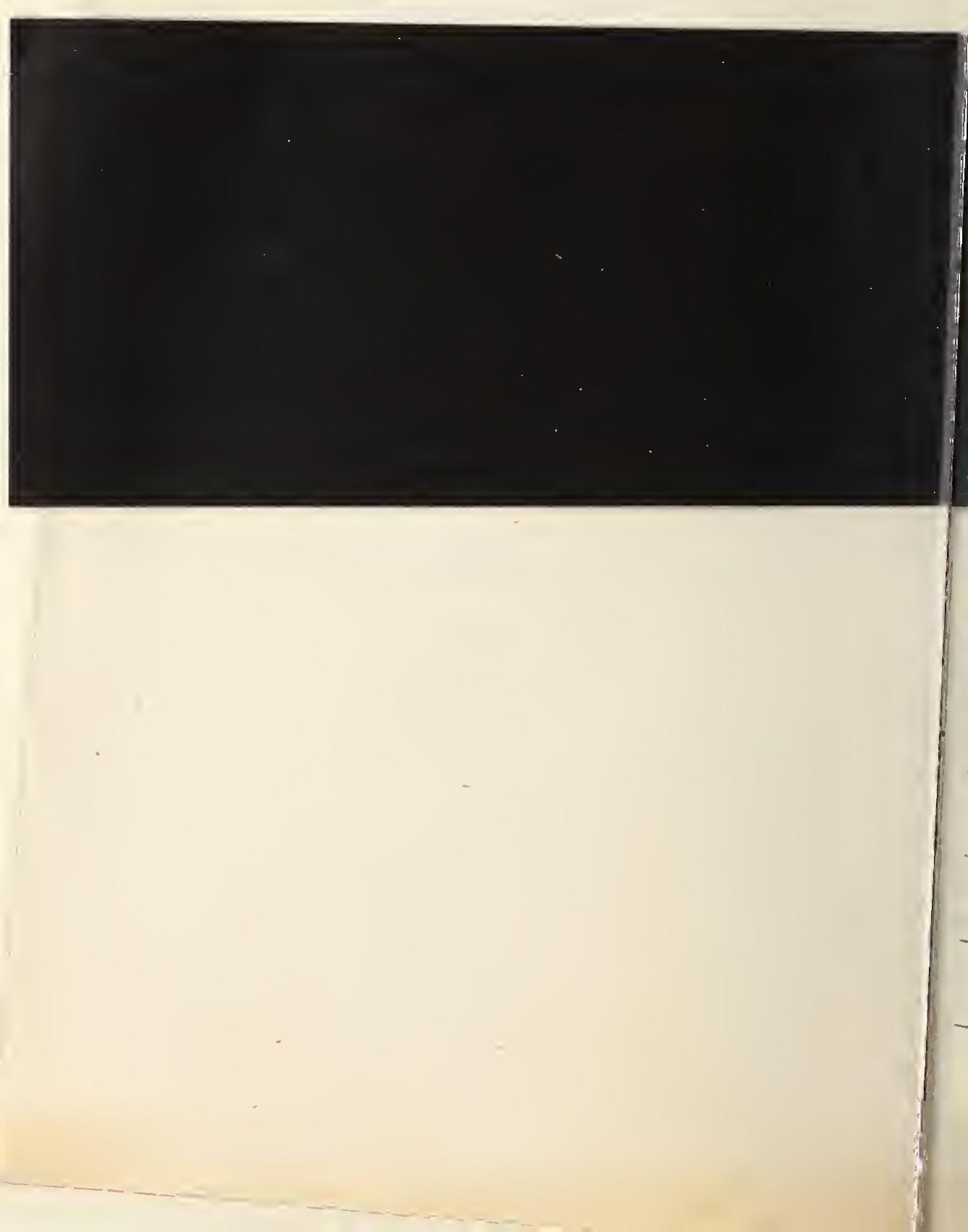




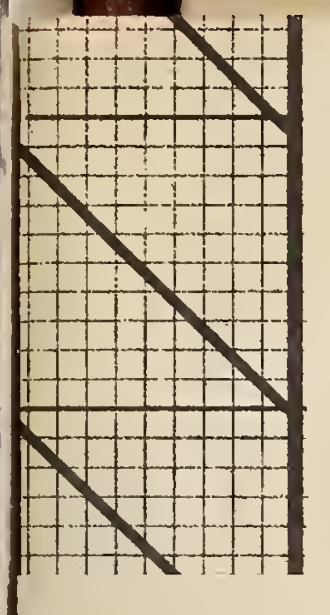

zynSS $\exists$ yd

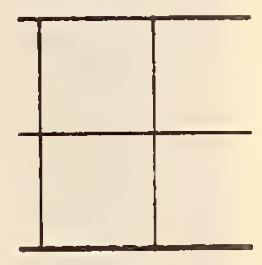

AS

slume

sture

rs

NDAR

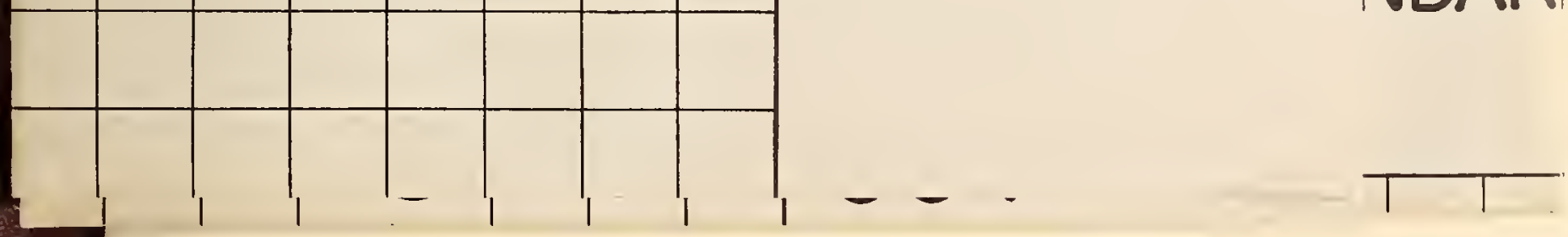





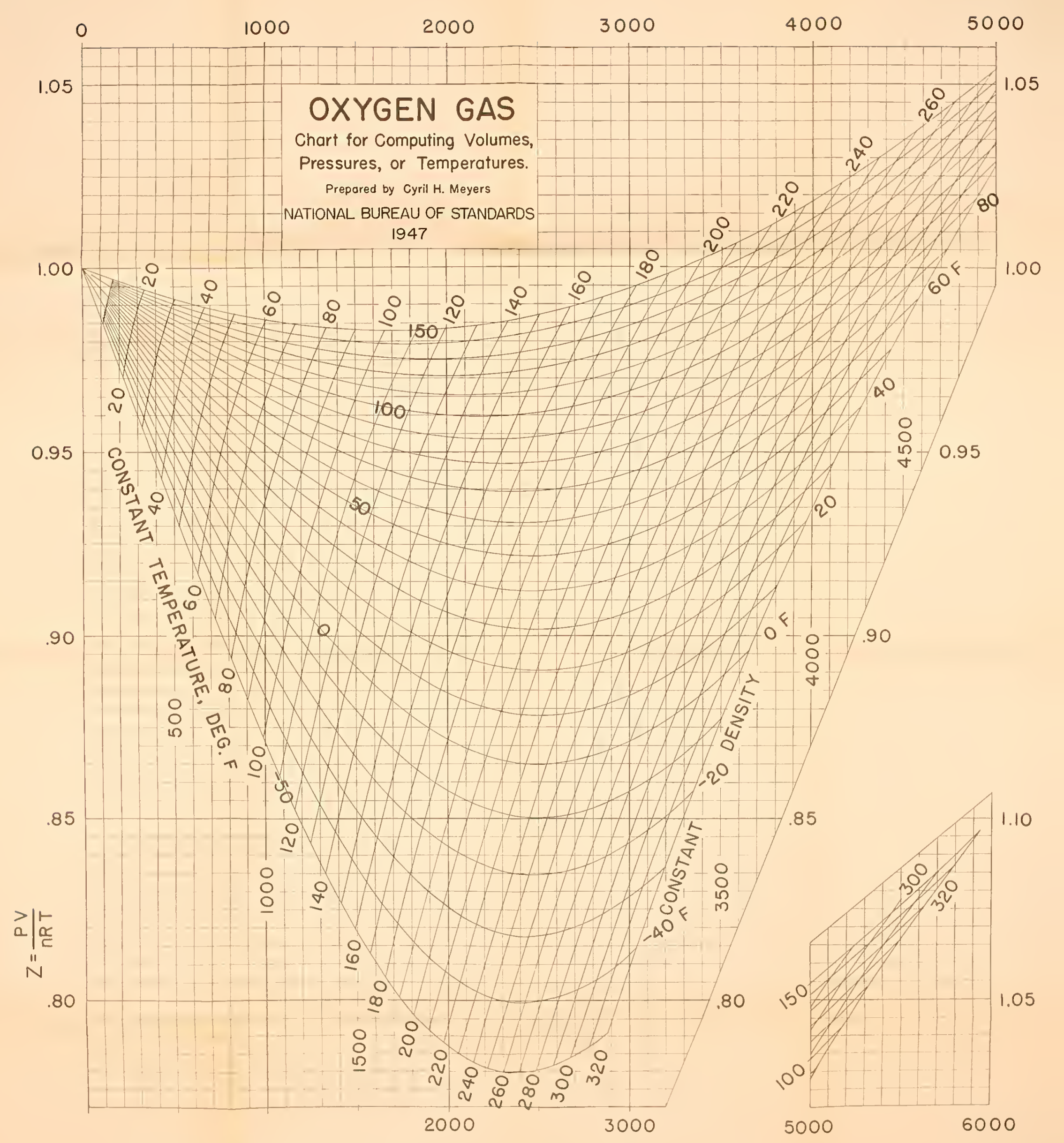

PRESSURE LBS.PER SQ.IN.ABS. 


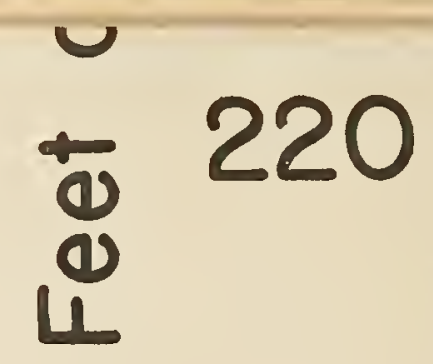

응

0009

00

:

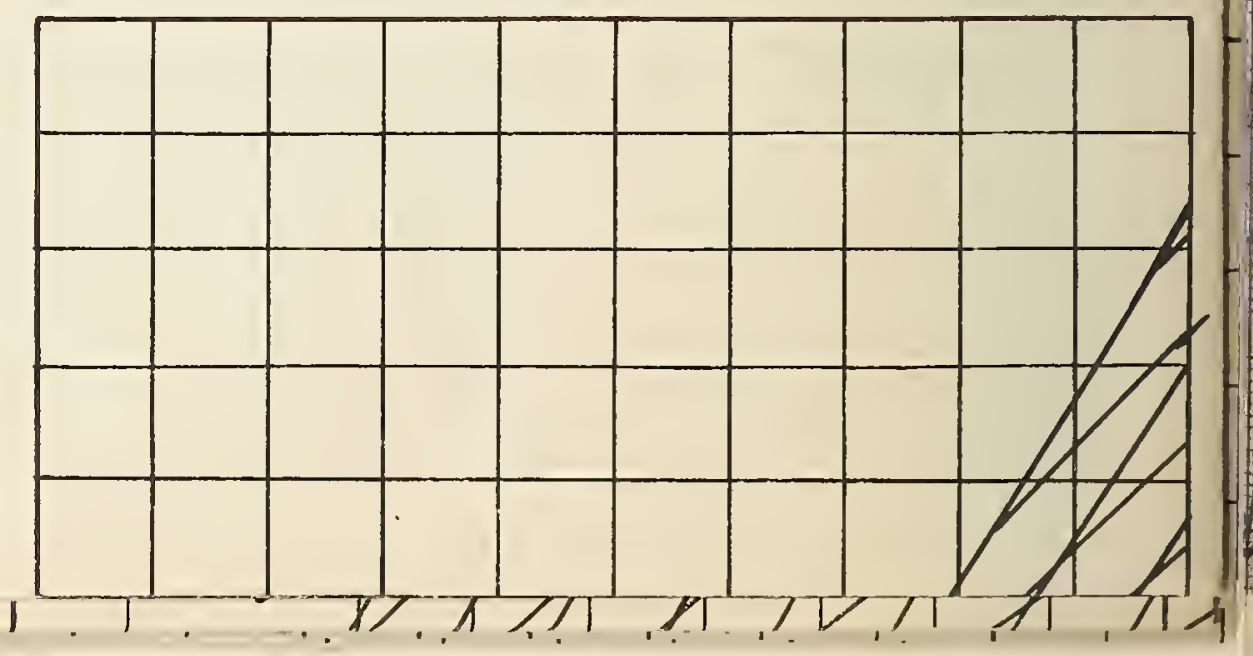




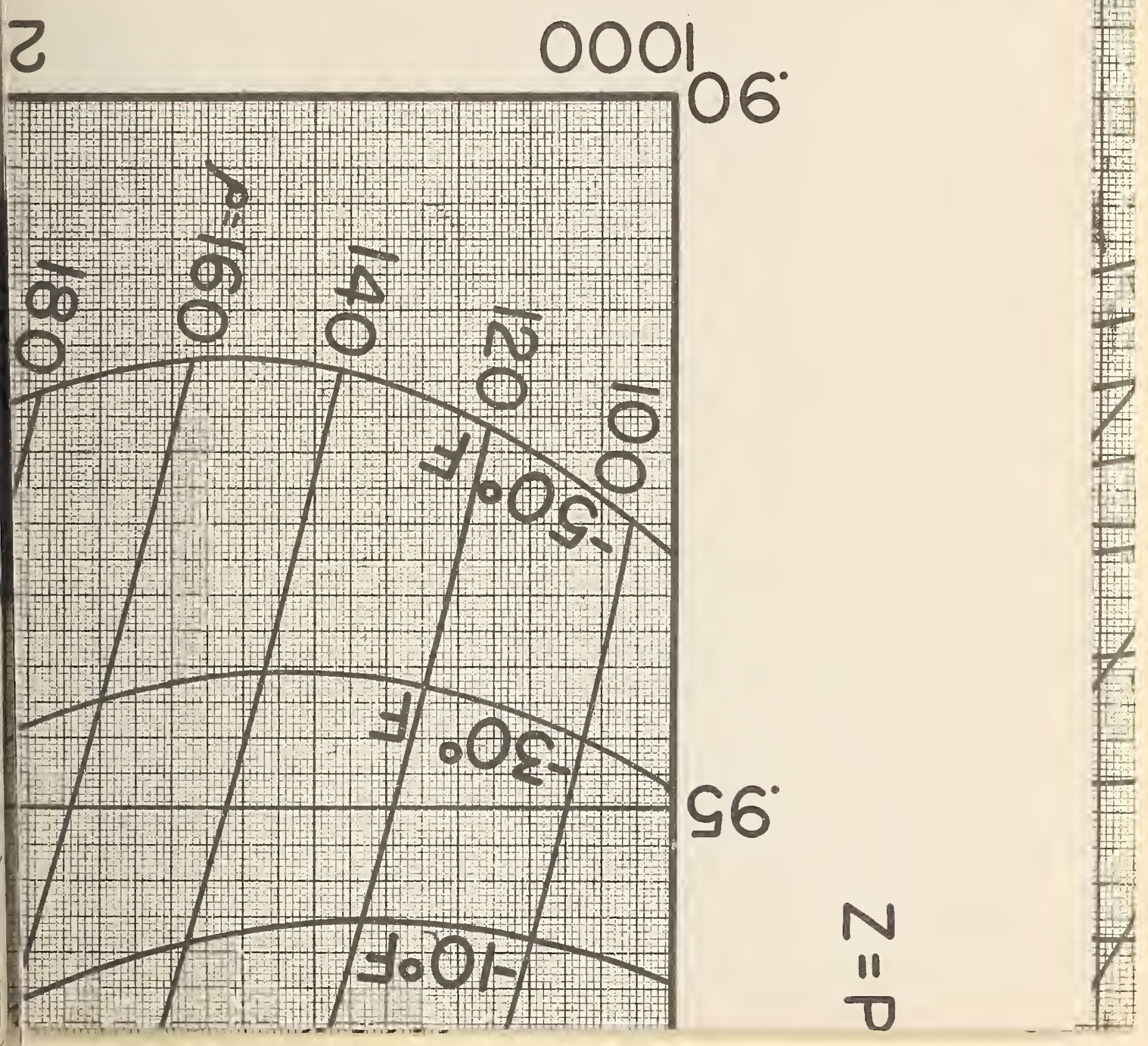




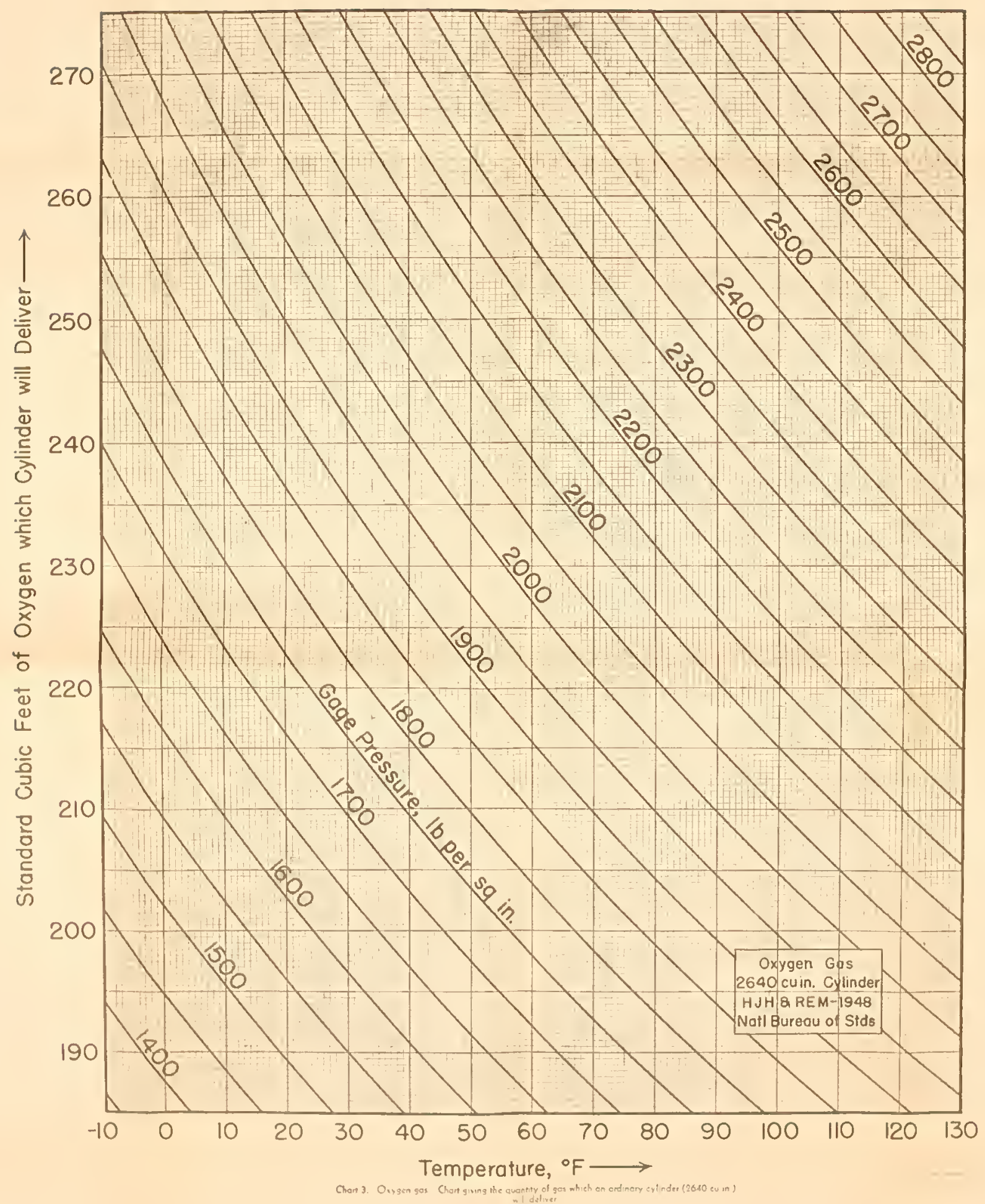



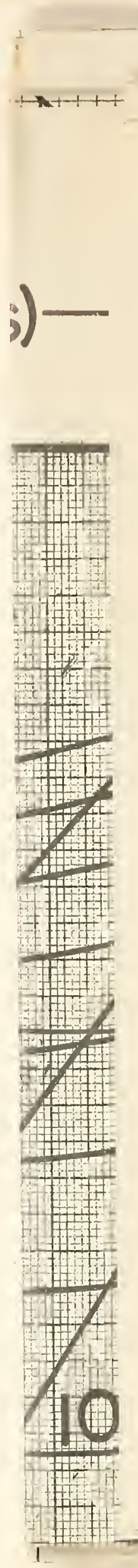

\section{9}
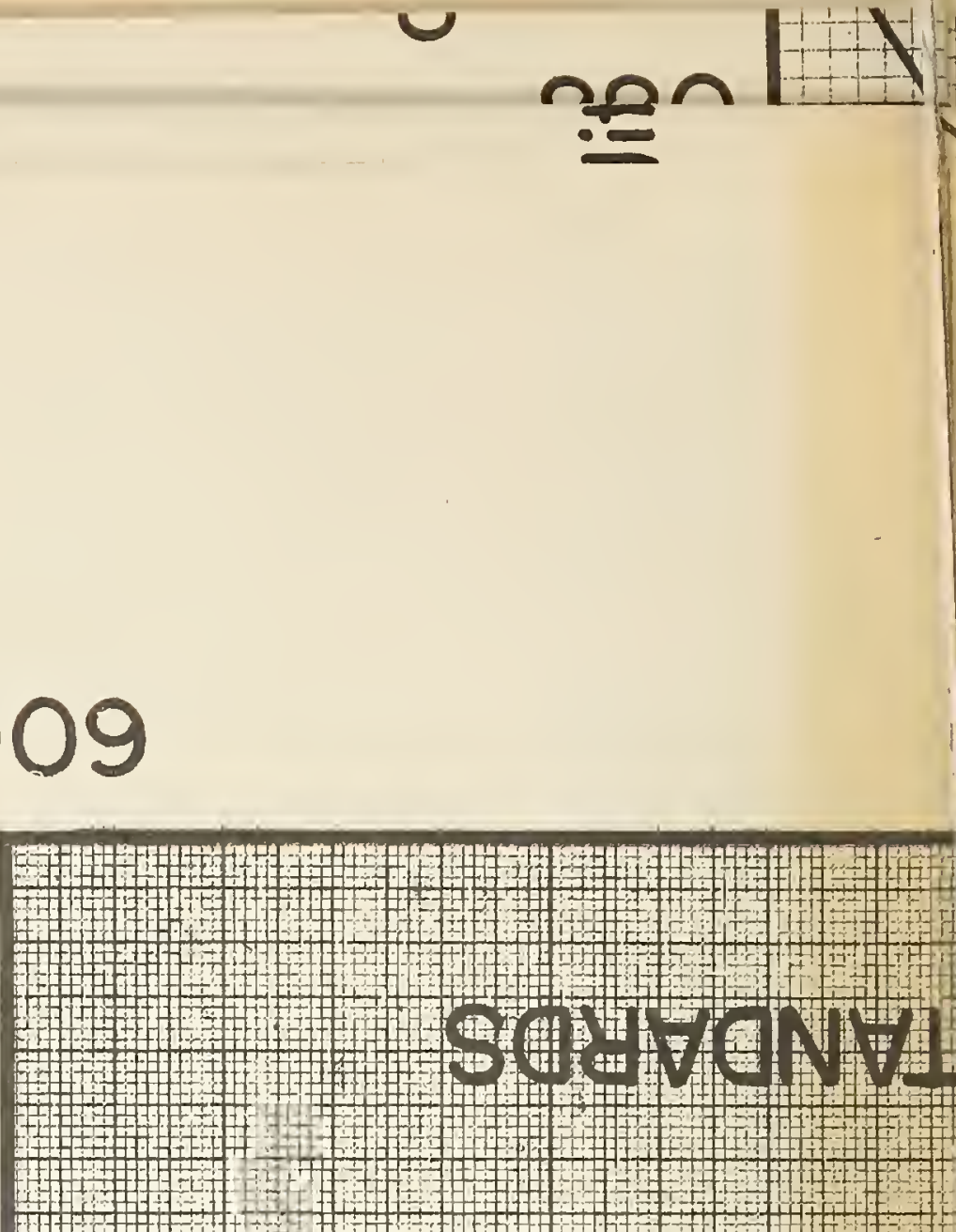

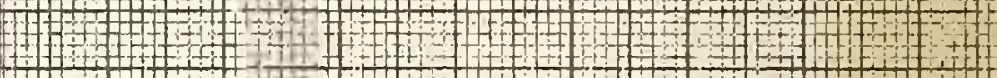

-

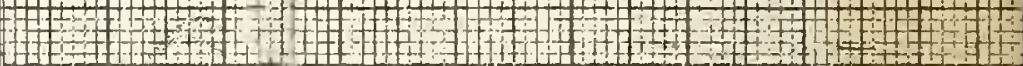
-

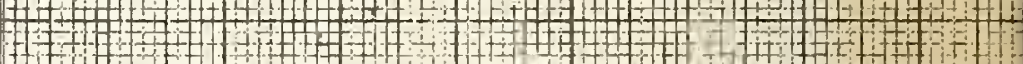

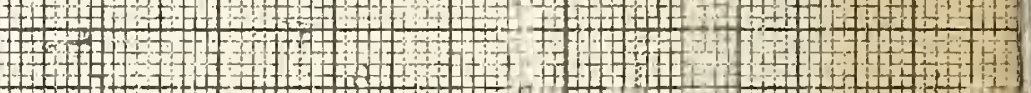

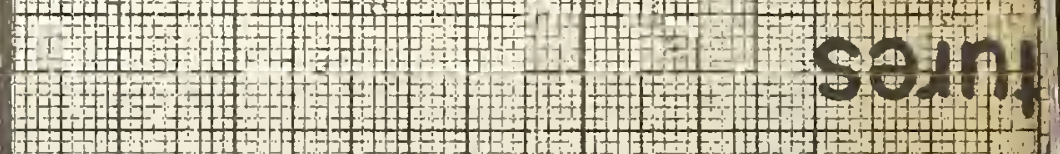

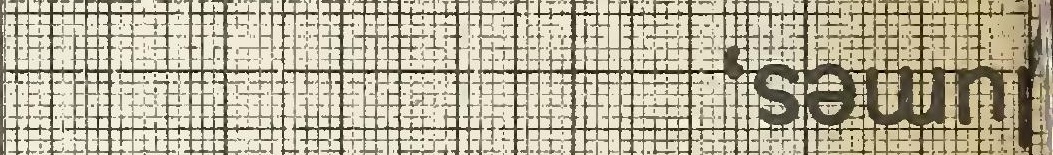

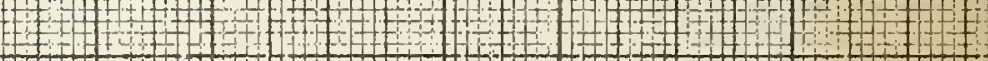

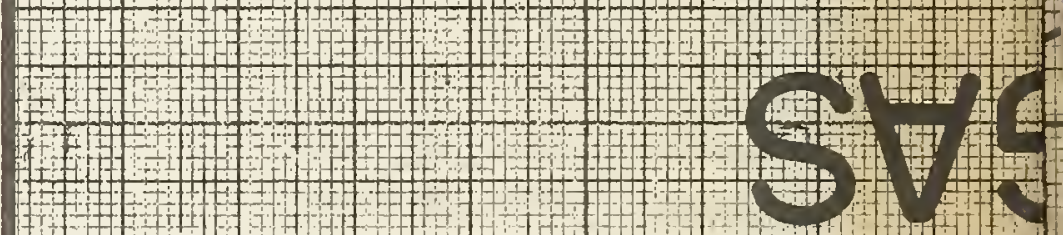

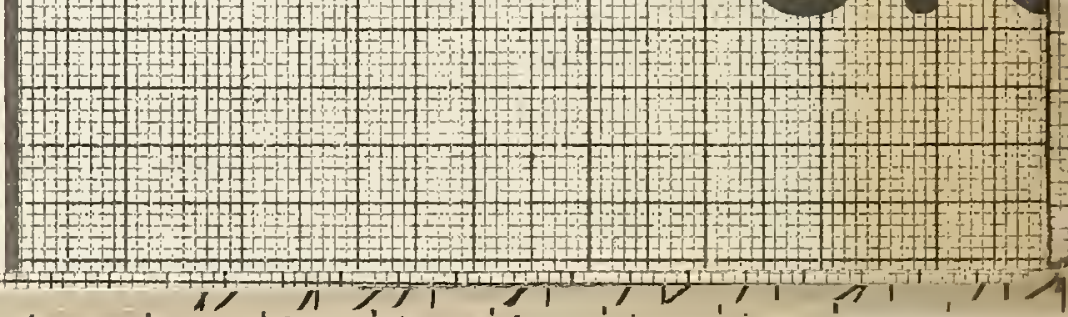


Pressure

\author{
A \\ NATIONAL BL
}




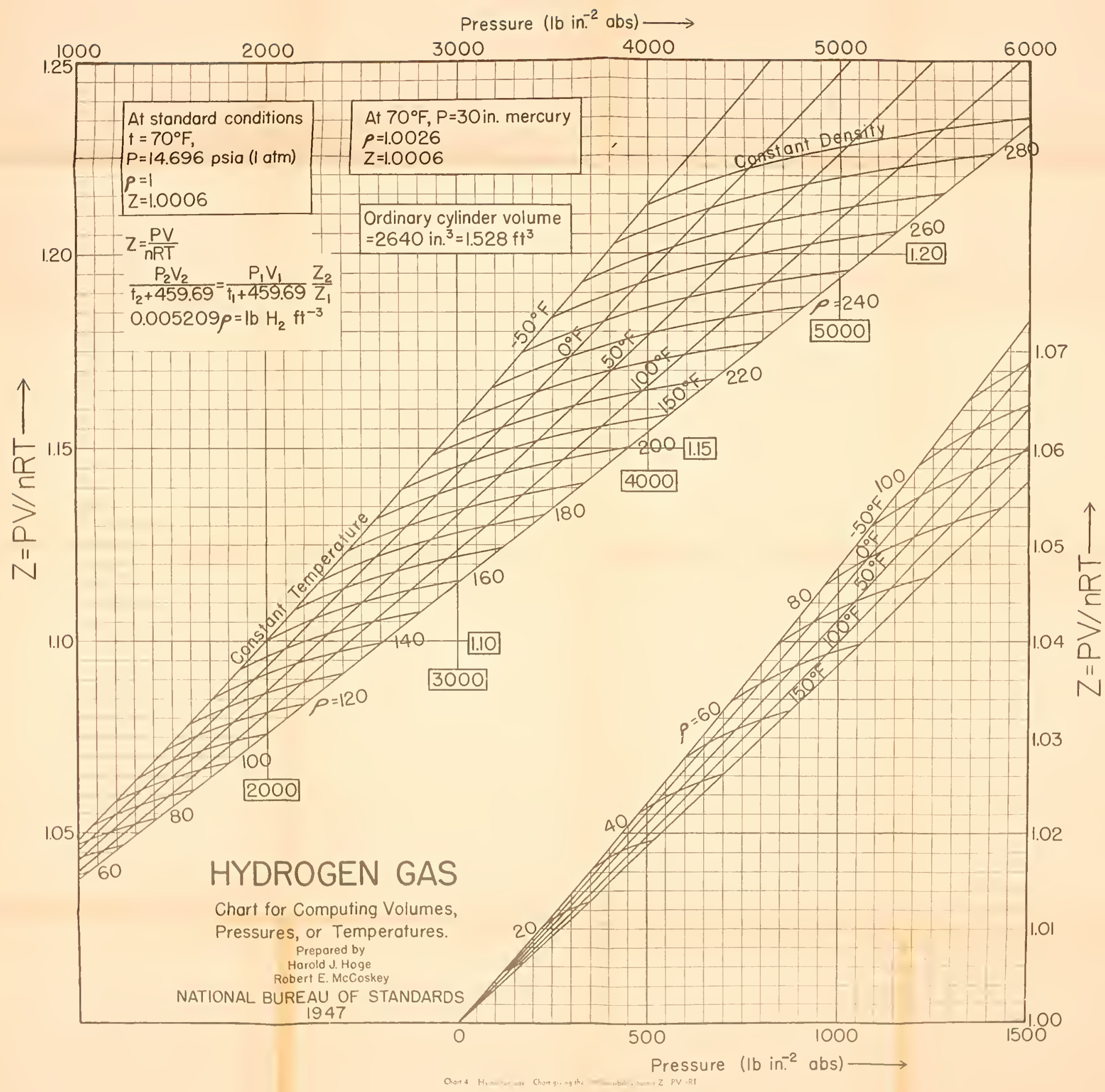





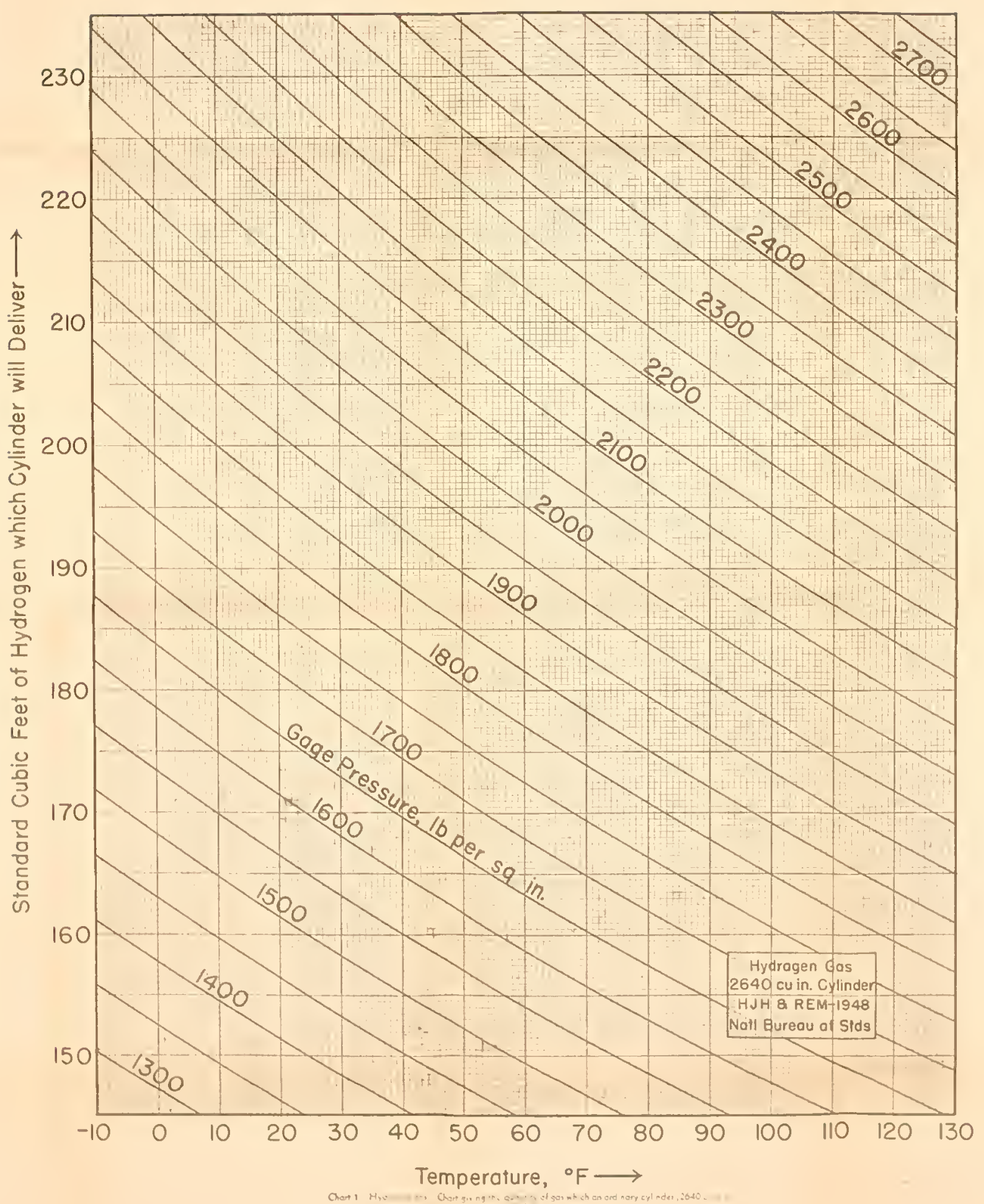




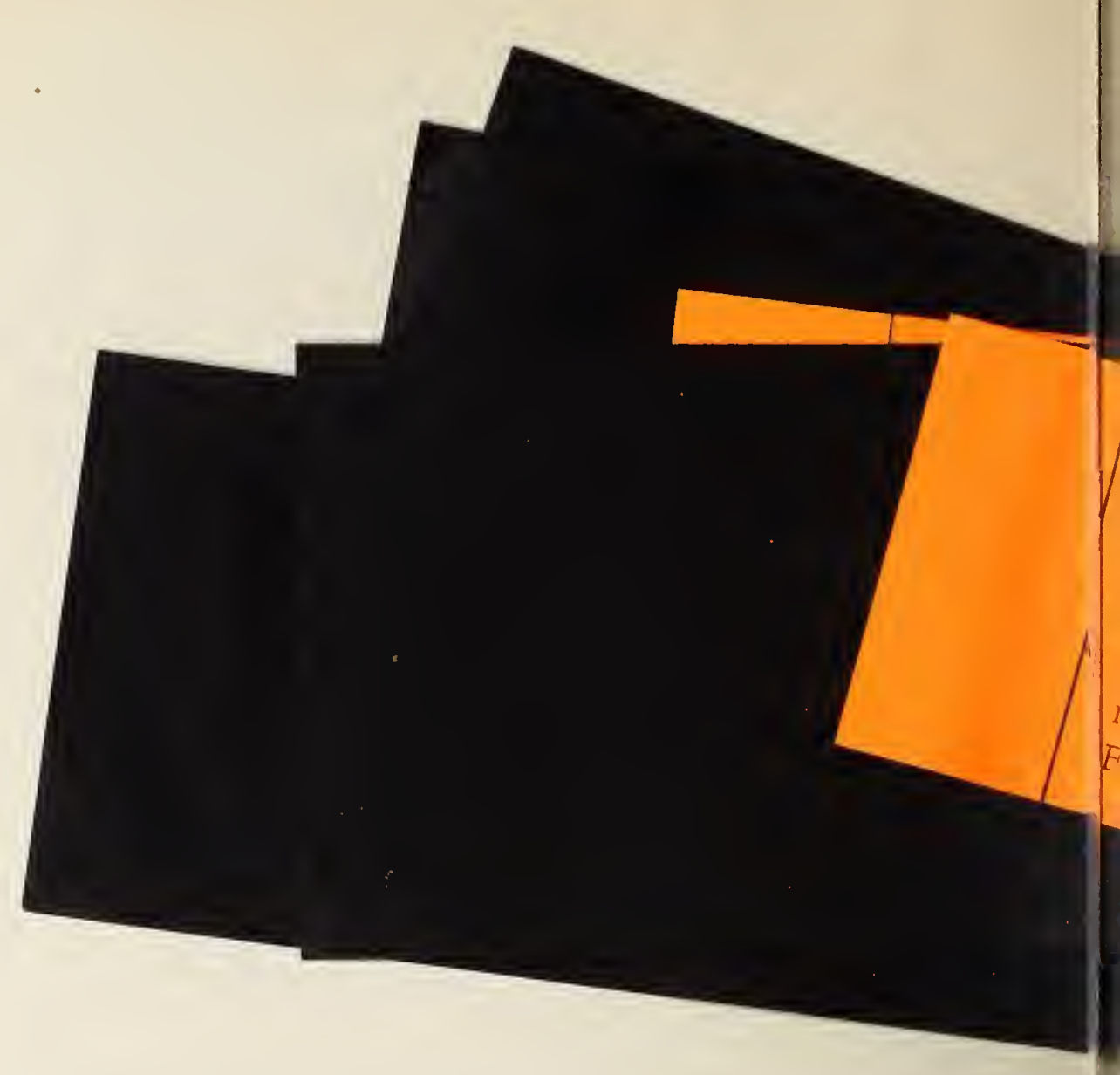


